\title{
Modified chain regression type estimator for population mean in the presence of non- response
}

\author{
B. B. Khare ${ }^{1}$, Habib Ur Rehman ${ }^{2 *}$ \\ ${ }^{1}$ Department of Statistics, Banaras Hindu University, Varanasi-221005 \\ ${ }^{2}$ Department of Community Medicine, R. D. Gardi Medical College, Ujjain (MP)-456006 \\ *Corresponding author E-mail:hrmbd007@gmail.com
}

\begin{abstract}
A modified chain regression type estimator for population mean in the presence of non-response have been proposed replacing Hansen \& Hurwitz (1946) estimator for population mean by Searls (1964) type improved estimator and using Hansen \& Hurwitz (1946) estimator for based on available information comparing to the study character in the second phase sample. The expressions for MSE for fixed sample size and also fixed cost have been obtained. The empirical studies show that the proposed estimator is more efficient than the relevant estimators in the case of fixed sample size as well as for fixed cost.
\end{abstract}

Keywords:Population Mean; Study Variable; Coefficient of Variation; Non- Response.

\section{Introduction}

The use of coefficient of variation in the estimation of population mean have been considered by Searls (1964, 1967), Sen (1978) and Das \& Tripathi (1980). In the case of non-response in the selected sample from the population, using Hansen and Hurwitz (1946) techniques of sub sampling from non-respondents. Khare and Srivastava $(1993,95)$ have proposed two phase sampling estimators for population mean in the presence of non-response. Further, Khare and Kumar $(2009,11)$ have proposed the estimators for population mean utilizing the coefficient of variation of the study character using auxiliary character in the presence of non-response. In the present paper, we have proposed modified chain regression type estimator for the population mean using known coefficient of variation of the study character in the presence of non-response and the Hansen \& Hurwitz (1946) estimator $\bar{x}^{*}$ for $\bar{X}$ using the available information on the second phase sample. The properties of their proposed estimator have been studied and a comparative study of the proposed estimator has been made with the relevant estimators. An empirical study has been given in the support of the proposed estimator used in the case of positive correlation as well as in the case of negative correlation between study and auxiliary characters for fixed sample size $\left(n^{\prime}, n\right)$ and also fixed $\operatorname{cost} C \leq C_{0}$.

\section{The estimators}

Let $(\overline{\mathrm{Y}}, \overline{\mathrm{X}})$ and $\left(\mathrm{C}_{\mathrm{y}}, \mathrm{C}_{\mathrm{x}}\right)$ denote the population means and coefficient of variation of the study variable $\mathrm{y}$ and auxiliary variablex. Here $(\bar{y}, \bar{x})$ denote the sample means of $(y, x)$ based on a sample of size $\mathrm{n}$ drawn from the population using SRSWOR method of sampling. In the case of non-response in the selected sample of size $\mathrm{n}$ for the study character $\mathrm{y}$, we observe that $\mathrm{n}_{1}$ units respond and $\mathrm{n}_{2}$ units do not respond. Further, a sub sample of size
$\mathrm{r}=\frac{\mathrm{n}_{2}}{\mathrm{~K}}(\mathrm{~K}>1)$ is drawn from $\mathrm{n}_{2}$ non-responding units by making extra efforts. Hansen and Hurwitz (1946) proposed an estimator for $\bar{Y}$ which is given as follows:

$$
\bar{y}^{*}=\frac{n_{1}}{n} \bar{y}_{1}+\frac{n_{2}}{n} \bar{y}_{2}^{\prime}
$$

Where $n_{1}$ and $n_{2}$ are the responding and non-responding units in a sample of size $n$ selected from population of size $N$ by SRSWOR method of sampling. $\bar{y}_{1}$ and $\bar{y}_{2}^{\prime}$ are the means based on $n_{1}$ and $r$ units selected from $n_{2}$ non-responding units by SRSWOR methods of sampling.

Similarly we can also define estimator for population mean $\bar{X}$ of auxiliary character $x$ based on $n_{1}$ and $r$ unit respectively, which is given as;

$\bar{x}^{*}=\frac{n_{1}}{n} \bar{x}_{1}+\frac{n_{2}}{n} \bar{x}_{2}^{\prime}$

Variance of the estimators $\bar{y}^{*}$ and $\bar{x}^{*}$ are given by

$V\left(\bar{y}^{*}\right)=\frac{f}{n} S_{y}^{2}+\frac{W_{2}(k-1)}{n} S_{y(2)}^{2}$

and

$V\left(\bar{x}^{*}\right)=\frac{f}{n} S_{x}^{2}+\frac{W_{2}(k-1)}{n} S_{x(2)}^{2}$

(4)

Where $f=1-\frac{n}{N}, W_{2}=\frac{N_{2}}{N},\left(S_{y}^{2}, S_{y(2)}^{2}\right)$ and $\left(S_{x}^{2}, S_{x(2)}^{2}\right)$ are population mean squares of $y$ and $x$ for entire population and nonresponding part of population.

In case, when $\overline{\mathrm{X}}$ is unknown, we select a large sample of size $\mathrm{n}^{\prime}(>n)$ from the population of size $\mathrm{N}$ by using SRSWOR method 
of sampling and we estimate $\overline{\mathrm{X}}$ by $\overline{\mathrm{x}}^{\prime}=\frac{1}{\mathrm{n}^{\prime}} \sum_{\mathrm{i}=1}^{\mathrm{n}^{\prime}} \mathrm{x}_{\mathrm{i}}$ and again draw a sub-sample of size $\mathrm{n}$ and observed $\mathrm{y}$ and $\mathrm{x}$ characters.

Two phase sampling regression estimators for population mean $\bar{Y}$ of the study character in the presence of non-response have been proposed by Khare and Srivastava (1995) and chain regression type estimators using additional auxiliary variable in two phase sampling in the presence of non-response have been proposed by Khare and Kumar (2010). Which are given as follows:

$$
\begin{aligned}
& T_{1}=\bar{y}^{*}+b^{*}\left(\bar{x}^{\prime}-\bar{x}^{*}\right) \\
& T_{2}=\bar{y}^{*}+b^{* *}\left(\bar{x}^{\prime}-\bar{x}\right)
\end{aligned}
$$

(6)

$\mathrm{T}_{3}=\overline{\mathrm{y}}^{*}+\mathrm{b}_{\mathrm{yx}}^{\prime}\left\{\overline{\mathrm{x}}^{\prime}+\mathrm{b}_{\mathrm{xz}}^{\prime}\left(\overline{\mathrm{z}}-\overline{\mathrm{z}}^{\prime}\right)-\overline{\mathrm{x}}\right\}$

$\mathrm{T}_{4}=\overline{\mathrm{y}}^{*}+\mathrm{b}_{\mathrm{yx}}^{\prime}\left\{\overline{\mathrm{x}}^{\prime}+\mathrm{b}_{\mathrm{xz}}^{\prime}\left(\overline{\mathrm{Z}}-\overline{\mathrm{z}}^{\prime}\right)-\bar{x}^{*}\right\}$

Where

$$
\begin{aligned}
& \bar{x}^{*}=\frac{n_{1}}{n} \bar{x}_{1}+\frac{n_{2}}{n} \bar{x}_{2}^{\prime}, \bar{x}=\frac{1}{n} \sum_{j=1}^{n} x_{j}, \bar{x}^{\prime}=\frac{1}{n^{\prime}} \sum_{j=1}^{n^{\prime}} x_{j}, b^{*}=\frac{\hat{S}_{y x}}{\hat{S}_{x}^{2}}, b^{* *}=\frac{\hat{S}_{y x}}{s_{x}^{2}}, \\
& s_{x}^{2}=\frac{1}{n-1} \sum_{i=1}^{n}\left(x_{i}-\bar{x}\right)^{2}, \mathrm{~b}_{\mathrm{yx}}^{\prime}=\frac{\hat{\mathrm{S}}_{\mathrm{yx}}}{\mathrm{s}_{\mathrm{x}}^{2}} \text { and } \mathrm{b}_{\mathrm{xz}}^{\prime}=\frac{\hat{S}_{\mathrm{xz}}}{\mathrm{s}_{\mathrm{z}}^{2}} .
\end{aligned}
$$

Using Searls (1964) method, Hansen \& Hurwitz (1946) estimator $\overline{\mathrm{y}}^{*}$ to be defined as $\overline{\mathrm{y}}^{* *}=a \overline{\mathrm{y}}^{*}$ for $\overline{\mathrm{Y}}$ in the presence of non-response, where $a$ is a constant. The value ofa, for which the $\operatorname{MSE}\left(\bar{y}^{* *}\right)$ will be minimum is given by:

$\mathrm{a}_{(\text {opt. })}=\left[1+\frac{\mathrm{f}}{\mathrm{n}} \frac{S_{\mathrm{Y}}^{2}}{\overline{\mathrm{Y}}^{2}}+\frac{\mathrm{W}_{2}(\mathrm{~K}-1)}{\mathrm{n}} \frac{S_{\mathrm{y}(2)}^{2}}{\overline{\mathrm{Y}}^{2}}\right]^{-1}$.

Since $\frac{S_{Y}^{2}}{\bar{Y}^{2}}$ and $\frac{S_{y(2)}^{2}}{\bar{Y}^{2}}$ do not differ significantly, so, we may approximate $\frac{\mathrm{S}_{\mathrm{y}(2)}^{2}}{\overline{\mathrm{Y}}^{2}}=\mathrm{C}_{\mathrm{y}}^{2}$ and neglecting the terms of order $\frac{1}{\mathrm{~N}}$, we have

$\hat{\mathrm{a}}_{(\mathrm{opt})}=\left[1+\frac{\mathrm{C}_{\mathrm{y}}^{2}}{\mathrm{n}}\left(1+\frac{\mathrm{W}_{2}}{\mathrm{n}}(\mathrm{K}-1)\right)\right]^{-1}$.

Now, we define an estimator $\overline{\mathrm{y}}^{* *}$ for $\overline{\mathrm{Y}}$ by improving the estimator $\overline{\mathrm{y}}^{*}$ using Searls(1964) method, which is given as follows:

$\overline{\mathrm{y}}^{* *}=\left[1+\frac{\mathrm{C}_{\mathrm{y}}^{2}}{\mathrm{n}}\left(1+\frac{\mathrm{w}_{2}}{\mathrm{n}}(\mathrm{K}-1)\right)\right]^{-1} \overline{\mathrm{y}}^{*}$

The mean square error (MSE) of $\bar{y}^{* *}$ is given as follows: $\operatorname{MSE}\left(\overline{\mathrm{y}}^{* *}\right)=(1-\mathrm{A}) \frac{\mathrm{S}_{\mathrm{y}}^{2}}{\mathrm{n}}+(1-2 \mathrm{~B}) \frac{\mathrm{W}_{2}(\mathrm{~K}-1)}{\mathrm{n}} \mathrm{S}_{\mathrm{y}(2)}^{2}$

Where, $A=\frac{C_{y}^{2}}{n}\left[1-W_{2}^{2}(K-1)^{2}\right]$ and $B=\frac{C_{y}^{2}}{n}\left[1+W_{2}(K-1)\right]$.

Comparing $\operatorname{MSE}\left(\overline{\mathrm{y}}^{* *}\right)$ with $\operatorname{MSE}\left(\overline{\mathrm{y}}^{*}\right)$, we see that

$\operatorname{MSE}\left(\overline{\mathrm{y}}^{* *}\right)<\operatorname{MSE}\left(\overline{\mathrm{y}}^{*}\right)$ When $1<a<1+\frac{1}{\mathrm{w}_{2}}$.

For the optimum choice ofa, the estimator $\overline{\mathrm{y}}^{*}$ may be improved by replacing a better estimator $\bar{y}^{* *}$ of $\bar{Y}$ than $\bar{y}^{*}$ in case of nonresponse. However the estimator $\bar{y}^{* *}$ may also be more efficient than $\bar{y}^{*}$ beyond the range ofa $>1+\frac{1}{\mathrm{w}_{2}}$.

Now, using known coefficient of variation of the study character, Khare \& Rehman (2014) have proposed chain regression type estimator for population mean in the presence of non-response, which is given as follows:

$\mathrm{T}_{\mathrm{R}}=\overline{\mathrm{y}}^{* *}+\hat{b_{1}}\left\{\overline{\mathrm{x}}^{\prime}+\hat{b_{2}}\left(\overline{\mathrm{Z}}-\overline{\mathrm{z}}^{\prime}\right)-\overline{\mathrm{x}}\right\}$

Further, the estimator $\mathrm{T}_{\mathrm{R}}$ is improved by replacing $\bar{x}^{*}$ in place of $\overline{\mathrm{x}}$. The proposed estimator $\mathrm{T}_{\mathrm{R} 1}$ is given as follows:

$\mathrm{T}_{\mathrm{R} 1}=\overline{\mathrm{y}}^{* *}+\hat{b_{1}}\left\{\overline{\mathrm{x}}^{\prime}+\hat{b_{2}}\left(\overline{\mathrm{Z}}-\overline{\mathrm{z}}^{\prime}\right)-\bar{x}^{*}\right\}$

Where $\hat{b_{1}}$ 团 $=\frac{\widehat{S}_{\mathrm{yx}}}{\mathrm{S}_{\mathrm{x}}^{2}}, \mathrm{~S}_{\mathrm{x}}^{2}=\frac{1}{\mathrm{~N}-\mathrm{S}_{\mathrm{X}}} \sum_{\mathrm{i}=1}^{\mathrm{N}}\left(\mathrm{X}_{\mathrm{i}}-\overline{\mathrm{X}}\right)^{2}, \widehat{\mathrm{S}}_{\mathrm{yx}}=\frac{1}{\mathrm{~N}-1} \sum_{\mathrm{i}=1}^{\mathrm{N}}\left(\mathrm{X}_{\mathrm{i}}-\overline{\mathrm{X}}\right)\left(\mathrm{Y}_{\mathrm{i}}-\right.$ $\overline{\mathrm{Y}}), \overline{\mathrm{y}}^{* *} \stackrel{\mathrm{S}_{\mathrm{x}}^{2}}{=} \mathrm{a} \overline{\mathrm{y}}^{*} \hat{b}_{2} \stackrel{\mathrm{N}-\mathrm{s}_{\mathrm{xz}}}{\mathrm{S}_{\mathrm{z}}^{2}}, \mathrm{~S}_{\mathrm{z}}^{2}=\frac{1}{\mathrm{~N}-1} \sum_{\mathrm{i}=1}^{\mathrm{N}}\left(\mathrm{Z}_{\mathrm{i}}-\overline{\mathrm{Z}}\right)^{2}, \widehat{\mathrm{S}}_{\mathrm{xz}}=$ $\frac{1}{\mathrm{~N}-1} \sum_{\mathrm{i}=1}^{\mathrm{N}}\left(\mathrm{X}_{\mathrm{i}}-\overline{\mathrm{X}}\right)\left(\mathrm{Z}_{\mathrm{i}}-\overline{\mathrm{Z}}\right)$.

$b_{1}$ 回 $=\frac{\hat{\mathrm{S}}_{\mathrm{yx}}}{\mathrm{S}_{\mathrm{x}}^{2}}, b_{2}=\frac{\hat{\mathrm{S}}_{\mathrm{xz}}}{\mathrm{S}_{\mathrm{z}}^{2}}, \widehat{\mathrm{S}}_{\mathrm{yx}}, \widehat{\mathrm{S}}_{\mathrm{zx}}$ and $\hat{S}_{x}^{2}$ are based on available data under the given sampling design.

In order to derive the expressions for the mean square error of the estimators:

Let $\overline{\mathrm{y}}^{*}=\overline{\mathrm{Y}}\left(1+\epsilon_{0}^{*}\right), \overline{\mathrm{x}}^{*}=\overline{\mathrm{X}}\left(1+\epsilon_{1}^{*}\right), \overline{\mathrm{x}}^{\prime}=\overline{\mathrm{X}}\left(1+\epsilon_{1}^{\prime}\right), \overline{\mathrm{x}}=\overline{\mathrm{X}}(1+$

$\left.\varepsilon_{1}\right)$ and $\overline{\mathrm{z}}^{\prime}=\overline{\mathrm{Z}}\left(1+\epsilon_{2}^{\prime}\right)$ such that $\mathrm{E}\left(\epsilon_{0}^{*}\right)=\mathrm{E}\left(\epsilon_{1}^{*}\right)=\mathrm{E}\left(\epsilon_{1}^{\prime}\right)=$

$\mathrm{E}\left(\epsilon_{2}^{\prime}\right)=\mathrm{E}\left(\epsilon_{1}\right)=0,\left|\epsilon_{0}^{*}\right|,\left|\epsilon_{1}^{*}\right|,\left|\epsilon_{1}^{\prime}\right|,\left|\epsilon_{2}^{\prime}\right|,\left|\epsilon_{1}\right|<1$.

By using simple random sampling without replacement method of sampling, we get,

$E\left(\epsilon_{0}^{* 2}\right)=\frac{1}{\bar{Y}^{2}} V\left(\bar{y}^{*}\right)=\frac{1}{\bar{Y}^{2}}\left\{\left(\frac{1}{n}-\frac{1}{N}\right) S_{y}^{2}+\frac{W_{2}(K-1)}{n} S_{y(2)}^{2}\right\}$

$E\left(\epsilon_{1}^{* 2}\right)=\frac{1}{\bar{X}^{2}} V\left(\bar{x}^{*}\right)=\frac{1}{\bar{X}^{2}}\left\{\left(\frac{1}{n}-\frac{1}{N}\right) S_{x}^{2}+\frac{W_{2}(K-1)}{n} S_{x(2)}^{2}\right\}$

$E\left(\epsilon_{1}^{\prime 2}\right)=\frac{1}{\bar{X}^{2}} V\left(\bar{x}^{\prime}\right)=\frac{1}{\bar{X}^{2}}\left(\frac{1}{n^{\prime}}-\frac{1}{N}\right) S_{x}^{2}$

$E\left(\epsilon_{2}^{\prime 2}\right)=\frac{1}{\bar{Z}^{2}} V\left(\bar{Z}^{\prime}\right)=\frac{1}{\bar{Z}^{2}}\left(\frac{1}{n^{\prime}}-\frac{1}{N}\right) S_{Z}^{2}$

$E\left(\epsilon_{1}^{2}\right)=\frac{1}{\bar{X}^{2}} V(\bar{x})=\frac{1}{\bar{Y} \bar{X}}\left\{\left(\frac{1}{n}-\frac{1}{N}\right) S_{y x}+\frac{W_{2}(K-1)}{n} S_{y x(2)}\right\}$

$E\left(\epsilon_{0}^{*}, \epsilon_{1}^{\prime}\right)=\frac{1}{\bar{Y} \bar{X}} \operatorname{COV}\left(\bar{y}^{*}, \bar{x}^{\prime}\right)=\frac{1}{\bar{Y} \bar{X}}\left(\frac{1}{n^{\prime}}-\frac{1}{N}\right) S_{y x}$

$E\left(\epsilon_{0}^{*}, \epsilon_{2}^{\prime}\right)=\frac{1}{\bar{Y} \bar{Z}} \operatorname{COV}\left(\bar{y}^{*}, \bar{z}^{\prime}\right)=\frac{1}{\bar{Y} \bar{Z}}\left(\frac{1}{n^{\prime}}-\frac{1}{N}\right) S_{y z}$

$E\left(\epsilon_{1}^{*}, \epsilon_{2}^{\prime}\right)=\frac{1}{\bar{X} \bar{Z}} \operatorname{COV}\left(\bar{x}^{*}, \bar{z}^{\prime}\right)=\frac{1}{\bar{X} \bar{Z}}\left(\frac{1}{n^{\prime}}-\frac{1}{N}\right) \mathrm{S}_{\mathrm{xz}}$

$\mathrm{E}\left(\epsilon_{1}^{*}, \epsilon_{1}^{\prime}\right)=\frac{1}{\overline{\mathrm{X}}^{2}} \operatorname{cov}\left(\overline{\mathrm{x}}^{*}, \overline{\mathrm{x}}^{\prime}\right)=\frac{1}{\overline{\mathrm{X}}^{2}} \mathrm{~V}\left(\overline{\mathrm{x}}^{\prime}\right)=\frac{1}{\overline{\mathrm{X}}^{2}}\left(\frac{1}{\mathrm{n}^{\prime}}-\frac{1}{\mathrm{~N}}\right) \mathrm{S}_{\mathrm{x}}^{2}$

$\mathrm{E}\left(\epsilon_{1}^{\prime}, \epsilon_{2}^{\prime}\right)=\frac{1}{\overline{\mathrm{X}} \overline{\mathrm{Z}}} \operatorname{COV}\left(\overline{\mathrm{x}}^{\prime}, \overline{\mathrm{z}}^{\prime}\right)=\frac{1}{\overline{\mathrm{X}} \overline{\mathrm{Z}}}\left(\frac{1}{\mathrm{n}^{\prime}}-\frac{1}{\mathrm{~N}}\right) \mathrm{S}_{\mathrm{xz}}$

The contribution of the terms involving the powers in $\epsilon_{0}^{*}, \epsilon_{1}^{*}, \epsilon_{1}^{\prime}, \varepsilon_{1}$ and $\epsilon_{2}^{\prime}$ of order higher than two in mean square errors are assumed to be negligible. So, the expressions for the MSE of the proposed estimator and relevant estimators will be considered up to the terms of order $\mathrm{n}^{-1}$.

\section{Mean square errors of the proposed estima- tor $T_{R 1}$}

The expression for the $\operatorname{MSE}\left(T_{R 1}\right)$ up to the form of order $\mathbf{n}^{-\mathbf{1}}$ is given as follows:

$\operatorname{MSE}\left(T_{R 1}\right)=(a-1)^{2} \bar{Y}^{2}+a^{2} V\left(\bar{y}^{*}\right)+\left(\frac{1}{n}-\frac{1}{n^{\prime}}\right)\left\{\bar{X}^{2} b_{1}^{2} C_{x}^{2}-2 \overline{X Y} \bar{Y} b_{1} C_{y x}\right\}$

$-\left(\frac{1}{n^{\prime}}-\frac{1}{N}\right)\left\{2 b_{1} b_{2} a \bar{Y} \bar{Z} C_{y z}-b_{1}^{2} b_{2}^{2} \bar{Z}^{2} C_{z}^{2}\right\}$

$+\frac{W_{2}(k-1)}{n}\left\{\bar{X}^{2} b_{1}^{2} C_{x(2)}^{2}-2 \overline{X Y} \overline{Y a} b_{1} C_{y x(2)}\right\}$ 
Where, $a_{(\text {opt. })}=\left[1+\frac{f}{n} \frac{S_{y}^{2}}{\bar{Y}^{2}}+\frac{W_{2}(K-1)}{n} \frac{S_{y(2)}^{2}}{\bar{Y}^{2}}\right]^{-1}$,

Mean square errors of the estimators $T_{1}, T_{2}, T_{3}, T_{4}$ and $T_{R}$ are given as follows:

$$
\begin{aligned}
& \operatorname{MSE}\left(T_{1}\right)=V\left(\bar{y}^{*}\right)-\bar{Y}^{2}\left(\frac{1}{n}-\frac{1}{n^{\prime}}\right) \rho_{y x}^{2} C_{y}^{2}+\frac{W_{2}(k-1)}{n}\left\{b_{1}^{2} C_{x(2)}^{2}-2 b_{1} C_{y x(2)}\right\} \\
& \operatorname{MSE}\left(T_{2}\right)=V\left(\bar{y}^{*}\right)-\bar{Y}^{2}\left(\frac{1}{n}-\frac{1}{n^{\prime}}\right) \rho_{y x}^{2} C_{y}^{2} \\
& \operatorname{MSE}\left(T_{3}\right)=V\left(\bar{y}^{*}\right)-\left(\frac{1}{n}-\frac{1}{n^{\prime}}\right) \bar{Y}^{2} \rho_{y x}^{2} C_{y}^{2}-\left(\frac{1}{n^{\prime}}-\frac{1}{N}\right) \bar{Y}^{2} \rho_{y x} \rho_{x z} C_{y}^{2}\left\{2 \rho_{y z}-\rho_{y x} \rho_{x z}\right\} \\
& \operatorname{MSE}\left(T_{4}\right)=V\left(\bar{y}^{*}\right)-\bar{Y}^{2}\left\{\left(\frac{1}{n}-\frac{1}{n^{\prime}}\right) \rho_{y x}^{2} C_{y}^{2}+\frac{1}{n^{\prime}} \rho_{y x} \rho_{x z} C_{y}^{2}\left\{2 \rho_{y z}-\rho_{y x} \rho_{x z}\right\}+\frac{W_{2}(k-1)}{n} \rho_{y x(2)}^{2} C_{y(2)}^{2}\right\} \\
& M S E\left(T_{R}\right)=(a-1)^{2} \bar{Y}^{2}+a^{2} V\left(\bar{y}^{*}\right)+\left(\frac{1}{n}-\frac{1}{n^{\prime}}\right) \bar{Y}^{2} \rho_{y x}^{2} C_{y}^{2}\{1-2 a\}-\frac{1}{n^{\prime}} \bar{Y}^{2} \rho_{y x} \rho_{x z} C_{y}^{2}\left\{2 a \rho_{y z}-\rho_{y x} \rho_{x z}\right\} \\
& \text { Where } \quad \mathrm{a}(\text { opt. })=\left[1+\frac{\mathrm{f}}{\mathrm{n}} \frac{\mathrm{S}_{\mathrm{y}}^{2}}{\overline{\mathrm{Y}}^{2}}+\frac{\mathrm{W}_{2}(\mathrm{~K}-1)}{\mathrm{n}} \frac{\mathrm{S}_{\mathrm{y}(2)}^{2}}{\overline{\mathrm{Y}}^{2}}\right]^{-1} \\
& \quad V\left(\bar{y}^{*}\right)=Y^{2}\left\{\frac{f}{n} C_{y}^{2}+\frac{W_{2}(k-1)}{n} C_{y(2)}^{2}\right\} \\
& \text { Where, }
\end{aligned}
$$

$\rho_{\mathrm{yx}(2)}=\frac{\mathrm{S}_{\mathrm{yx}(2)}}{\mathrm{S}_{\mathrm{y}(2)} \mathrm{S}_{\mathrm{x}(2)}}$ And $\left(\mathrm{S}_{\mathrm{yx}(2)}, \rho_{\mathrm{yx}(2)}\right)$ denote the covariance and correlation between $\mathrm{y}$ and $\mathrm{x}$ characters for the non response group of the population.

\section{Determination of $n^{\prime}, n$ and $k$ for the fixed cost $C \leq C_{0}$}

Let us assume that $C_{0}$ be the total cost (fixed) of the survey apart from overhead cost. The expected total cost of the survey apart from overhead cost is given as follows:

$$
C=\left(h_{1}^{\prime}+h_{2}^{\prime}\right) n^{\prime}+n\left(h_{1}+h_{2} W_{1}+h_{3} \frac{W_{2}}{k}\right) \text {, }
$$

Where

$h_{1}^{\prime}$ : The cost per unit of obtaining information on auxiliary character $x$ at the first phase.

$h_{2}^{\prime}$ : The cost per unit of obtaining information on additional auxiliary character $Z$ at the first phase.

$h_{1}$ : The cost per unit of mailing questionnaire/visiting the unit at the second phase.

$h_{2}$ : The cost per unit of collecting, processing data obtained from $n_{1}$ responding units.

$h_{3}$ : The cost per unit of obtaining and processing data (after extra efforts) for the sub sampling units.

The expression for, $\operatorname{MSE}\left(T_{R 1}\right)$ can be expressed in terms of $H_{0}, H_{1}, H_{2}$ and $H_{3}$ which are the coefficients $\frac{1}{n}, \frac{1}{n^{\prime}}, \frac{k}{n}$ and $\frac{1}{N}$ respectively. The expression of $M S E\left(T_{R 1}\right)$ is given as follows:

$\operatorname{MSE}\left(T_{R 1}\right)_{\min }=\frac{H_{0}}{n}+\frac{H_{1}}{n^{\prime}}+\frac{k H_{2}}{n}-\frac{H_{3}}{N}$

For obtaining the optimum values of $n^{\prime}, n, k$ for the fixed cost $C \leq C_{0}$, we define a function $\varphi$ which is given as:
$\varphi=\operatorname{MSE}\left(T_{R 1}\right)_{\min }+\mu\left(C-C_{0}\right)$,

Where $\mu$ is the Lagrange's multiplier?

We differentiating $\varphi$ with respect to $n^{\prime}, n, k$ and equating zero, we get optimum values of $n^{\prime}, n$ and $\mathrm{k}$. which are given as follows:

$$
\begin{aligned}
& n_{o p t}^{\prime}=\sqrt{\frac{H_{1}}{\mu\left(h_{1}^{\prime}+h_{2}^{\prime}\right)}}, \\
& n_{o p t}=\sqrt{\frac{\left(H_{0}+k_{o p t} H_{2}\right)}{\mu\left(h_{1}+h_{2} W_{1}+h_{3} \frac{W_{2}}{k_{o p t}}\right)}},
\end{aligned}
$$

and

$$
k_{\text {opt }}=\sqrt{\frac{H_{0} h_{3} W_{2}}{H_{2}\left(h_{1}+h_{2} W_{1}\right)}},
$$

Where

$$
\sqrt{\mu}=\frac{1}{C_{0}}\left[\sqrt{H_{1}\left(h_{1}^{\prime}+h_{2}^{\prime}\right)}+\sqrt{\left(H_{0}+k_{\text {opt }} H_{2}\right)\left(h_{1}+h_{2} W_{1}+h_{3} \frac{W_{2}}{k_{\text {opt }}}\right)}\right]
$$

The minimum value of $\operatorname{MSE}\left(T_{R 1}\right)$ for the optimum values of $n^{\prime}, n$ and $\mathrm{k}$ in the expression $\operatorname{MSE}\left(T_{R 1}\right)$, we get:

$\operatorname{MSE}\left(T_{R 1}\right)=\frac{1}{C_{0}}\left[\sqrt{+\sqrt{\left(H_{0}+k_{\text {opt }} H_{2}\right)\left(h_{1}+h_{2} W_{1}+h_{3} \frac{W_{2}}{k_{\text {opt }}}\right)}}\right]^{2}-\frac{H_{3}}{N}$

Now neglecting the term of $\mathrm{O}\left(N^{-1}\right)$, we have

$$
\operatorname{MSE}\left(T_{R 1}\right)_{\min }=\frac{1}{C_{0}}\left[\sqrt{H_{1}\left(h_{1}^{\prime}+h_{2}^{\prime}\right)}+\sqrt{\left(H_{0}+k_{o p t} H_{2}\right)\left(h_{1}+h_{2} W_{1}+h_{3} \frac{W_{2}}{k_{o p t}}\right)}\right]^{2}
$$

\section{An empirical study}

To illustrate the results, we have observed the data given by Khare and Sinha (2007). The description of the population is given below: The data on physical growth of upper socio-economic group of 95 school children of Varanasi under an ICMR study, Department of Pediatrics, B.H.U., during 1983-84 has been taken under the study The first $25 \%$ (i. e. 24 children) units have been considered as non-responding units. Here we denote the study character $(y)$, auxiliary character $(x)$ and the additional auxiliary character $(z)$. Which are given as follows?

$y$ : Weight (in kg.) of the children.

$x:$ Skull circumference (in $\mathrm{cm}$ ) of the children.

$z$ : Chest circumference (in $\mathrm{cm}$ ) of the children.

The values of the parameters of the $y, x$ and $z$ characters for the given data are given as follows:

$\bar{Y}=19.4968, \quad \bar{Z}=51.1726, \bar{X}=55.8611, C_{y}=0.15613$,

$C_{z}=0.03006, C_{x}=.05860, C_{y(2)}=0.12075, C_{z(2)}=0.02478$,

$C_{x(2)}=0.05402, \rho_{y z}=0.328, \rho_{y x}=0.846, \rho_{x z}=0.297, \rho_{x z(2)}=0.570$,

$W_{2}=0.25, W_{1}=0.74, N=95, n=35$ 
Table 1: Relative Efficiency (in \%) of the Estimators with Respect To $\bar{y}^{*}$ for the Fixed Values of $n^{\prime}, \boldsymbol{n}$ For Different Values of $k$ ( $N=95, n^{\prime}$ $=70$ and $n=35$ )

\begin{tabular}{llll}
\hline Estimators & \multicolumn{1}{c}{$1 / k$} \\
\hline $\bar{y}^{*}$ & $100(0.3658)^{*}$ & $100(0.2996)$ & $1 / 3$ \\
$T_{1}$ & $125(0.2933)$ & $136(0.2197)$ & $159(0.1461)$ \\
$T_{2}$ & $135(0.2710)$ & $146(0.2048)$ & $168(0.1387)$ \\
$T_{3}$ & $137(0.2657)$ & $149(0.2013)$ & $173(0.1351)$ \\
$T_{4}$ & $246(0.1491)$ & $245(0.1224)$ & $242(0.0957)$ \\
$T_{R}$ & $146(0.2234)$ & $162(0.1833)$ & $192(0.1186)$ \\
$T_{R 1}$ & $316(0.1156)$ & $309(0.0967)$ & $299(0.0779)$ \\
\hline *Figures in parenthesis give the MSE $()$. &
\end{tabular}

From table 1, we observed that for the fixed sample sizes $\left(n^{\prime}, n\right)$, the proposed estimators $T_{R 1}$ is more efficient in comparison to the estimators $\bar{y}^{*}, T_{1}, T_{2}, T_{3}, T_{4}$ and $T_{R}$. Hence we propose to use the estimator $T_{R 1}$ in practice using the given information on the coefficient of variation of the study character.

Table 2: Relative Efficiency (In \%) of the Estimators with Respect to $\bar{y}^{*}$ (for the Fixed Cost $C \leq C_{0}=$ Rs.220, $c_{1}^{\prime}=$ Rs. 0.90, $c_{2}^{\prime}=$ Rs. 0.10, $c_{1}=$ Rs. 2 , $c_{2}=$ Rs. $4, c_{3}=$ Rs. 25).

\begin{tabular}{lllll}
\hline Estimators & $k_{o p t}$ & $n_{o p t}^{\prime}$ & $n_{o p t}$ & Efficiency \\
\hline $\bar{y}^{*}$ & 2.68 & --- & 30 & $100(0.38429)^{*}$ \\
$T_{1}$ & 1.30 & 75 & 15 & $138(0.27875)$ \\
$T_{2}$ & 1.07 & 76 & 14 & $136(0.28185)$ \\
$T_{3}$ & 1.03 & 72 & 22 & $147(0.25172)$ \\
$T_{4}$ & 1.10 & 65 & 19 & $157(0.22567)$ \\
$T_{R}$ & 1.02 & 84 & 18 & $160(0.21246)$ \\
$T_{R 1}$ & 1.09 & 85 & 16 & $185(0.18572)$ \\
\hline
\end{tabular}

*Figures in parenthesis give the MSE (.).

From table 2, we obtained that for the fixed cost $C \leq C_{0}$ the proposed estimators $T_{R 1}$ is more efficient in comparison to the estimators $\bar{y}^{*}, T_{1}, T_{2}, T_{3}, T_{4}$ and $T_{R}$.

\section{Conclusion}

Hence, we conclude that the use of coefficient of variation of the study character increase the efficiency of proposed estimator $T_{R 1}$ is more efficient to relevant estimators $\bar{y}^{*}, T_{1}, T_{2}, T_{3}, T_{4}$ and $T_{R}$. The values of $n^{\prime}$ and $n$ have been changed which makes the estimator more efficient than the relevant estimators in case of fixed cost using $\bar{x}^{*}$, replace of $\bar{x}$ in estimator $T_{R}$, we have been obtained modified estimator $T_{R 1}$ is more efficient from the estimator $T_{R}$ in case of fixed sample size and fixed cost.

\section{References}

[1] Das, A. K., Tripathi, T. P. (1980). Sampling strategies for population mean when the coefficient of variation of an auxiliary character is known. Sankhya C-42: 76-86.

[2] Hansen, M. H. and Hurwitz, W. N. (1946). The problem of nonresponse in sample surveys. J. Amer. Stat. Assoc., 41, $517-$ 529.http://dx.doi.org/10.1080/01621459.1946.10501894.
[3] Khare, B. B. and Srivastava, S. (1993). Estimation of population mean using auxiliary character in presence of non-response. Nat. Acad. Sci. Latt, India, 16(3), 111-114.

[4] Khare, B. B. and Srivastava, S. (1995). Study of conventional and alternative two phase sampling ratio, product and regression estimators in presence of non-response. Proc. Nat. Acad. Sci., India, Sect. a 65(a) II, 195-203.

[5] Khare, B. B. and Sinha, R.R. (2007).Estimation of the ratio of the two population means using multi- auxiliary characters in presence of nonresponse. In "Statistical techniques in life testing, reliability, sampling theory and quality control" edited by B.N.Pandey. Narosa publishing house, New Delhi, 163-171.

[6] Khare, B.B. and Kumar, S. (2009). Utilization of coefficient of variation in the estimation of population mean using auxiliary character in the presence of non-response. Nat. Acad. Sci. Letters, India, Vol. 32, No. $(7 \& 8), 235-241$.

[7] Khare, B. B. and Kumar, S. (2010). Chain regression type estimators using additional auxiliary variable in two phase sampling in the presence of non-response. Nat. Acad. Sci. Letters, India, 33, No. (11 \& 12) 369-375.

[8] Khare, B.B. and Kumar, S. (2011). Estimation of population mean using known coefficient of variation of the study character in the presence of non-response. Commun. Stats.-Theor. \& Meth, Vol. 40, 1-15. http://dx.doi.org/10.1080/03610921003725820.

[9] Khare, B.B. and Rehman, H.U. (2014). Generalized chain regression type estimator for population mean using known coefficient of variation of the study character in the presence of non-response. Int. Jour. Maths. Stats, Vol. 15 (3), 54-60.

[10] Searls, D. T (1964). The utilization of a known coefficient of variation in the estimation procedure. J. Amer. Stat. Assoc. 59:12251226.http://dx.doi.org/10.1080/01621459.1964.10480765.

[11]Searls, D. T. (1967). A note on the use of an approximately known coefficient of variation. J. Amer. Stat. Assoc. 21:20-21.

[12]Sen, A. R. (1978). Estimation of the population mean when the coefficient of variation is known. Commun. Stats. Theor. \& Meth, A7 (7):657-672.http://dx.doi.org/10.1080/03610927808827656. 